Journal of Mathematics and Informatics

Vol. 19, 2020, 1-5

ISSN: 2349-0632 (P), 2349-0640 (online)

Published 2 July 2020

www.researchmathsci.org

DOI: http://dx.doi.org/10.22457/jmi.v19a01175

Journal of

Mathematics and

Informatics

\title{
A Evaluation Model about Development Strategy of Fishery Companies Based on AHP Method
}

\author{
Jia-feng Xiao ${ }^{{ }^{*}}$ and Zhi-xu Huang ${ }^{2}$ \\ College of Science, Chongqing University of Posts and Telecommunications \\ Chong'qing, China. \\ ${ }^{2}$ E-mail: huangzx0329@163.com \\ ${ }^{*}$ Corresponding author. ${ }^{1}$ E-mail: Xjiafeng2000@163.com
}

Received 2 May 2020; accepted 1 July 2020

\begin{abstract}
Changes in ocean temperature are closely related to the growth and reproduction of marine life, and also affect the development of fisheries. With the rise of the ocean temperature, the migration of Scottish herring and mackerel has had a significant impact on the development of the Scottish fishing economy and fishing companies. This article will use the Analytic Hierarchy Process (AHP) to establish a practical economic strategy evaluation model for the future development of the Scottish fishing companies, and then provide some reasonable suggestions.
\end{abstract}

Keywords: rise of the ocean temperature, AHP, economic strategy evaluation model

\section{AMS Mathematics Subject Classification (2010): 03H10}

\section{Introduction}

Analytic Hierarchy Process (AHP) is a decision-making method that decomposes elements related to decision-making into goals, criteria, plans and other levels, which performs qualitative and quantitative analysis on this basis.

The method was first proposed by American operations researcher Professor Saaty [1] in the University of Pittsburgh in the early 1970s, which was used to solve the US Department of Defense research "contingency plan". In 1982, AHP was introduced into China by Saaty's student Lanchai. Subsequently, Xu and others published the first domestic article ("AHP — a practical method of decision-making") introducing AHP . Since then, the AHP method has been rapidly developed in China, and it has been widely used in economic planning and management [2], energy policy and distribution, urban competitiveness [3], talent selection and evaluation [4], transportation, research topics and so on.

The application basis of AHP is to have certain information materials for complex decision-making problems [5]. We can analyze its nature and related influencing factors as well as internal and external relationships, and then use quantitative information to quantify the complex decision-making problem. After doing that,we can turn the complex problem into a simple mathematical operation.

The AHP method has been continuously improved in the development, in addition, some new theories and methods have also been formed in its application. 


\section{Jia-feng Xiao and Zhi-xu Huang}

As for the northward migration of Scottish herring and mackerel, fishery companies have been the most affected. However, facing with the migration of these two major economic fishes, the strategic changes that Scottish fishery companies make cannot be directly quantified by quantitative indicators. Based on this, we consider combining the development goals of fishery companies with feasible change strategies to establish a Hierarchical Analysis Model for practical economic strategy evaluation. By establishing this model, the corresponding strategies can be scored and sequenced, which provides a quantifiable measure for the change of fishery companies' management strategies.

\section{Background}

Mackerel and herring are one of the important economic fishes in Scotland. The arrival of these two pelagic fishes has caused the value of fisheries in Scotland continue to rise and hit the highest level of output value in history. However, as the global climate warms and the sea temperature gradually rises, Scottish herring and mackerel will also move towards the northern oceans where the temperature is lower [6]. The migration of the two economic fish species has affected the development of the Scottish fishery economy, which also hits Fishery companies that have made a living by fishing. In the context of the gradual migration of herring and mackerel, how to change the development strategy of fishery companies has become a hot topic in public. In this article, we will evaluate some feasible strategies for the future development of the fishery company through the Analytic Hierarchy Process and then make some reasonable suggestions.

\section{The model}

We conducted statistical analysis and charted the collected data [7] on the annual tonnage of different fishes caught in Scotland in recent years. After that, we can visually see the changes in the tonnage of herring and mackerel from Figure 1.

From Figure 1, we can see that although the proportion of the two fish species has declined with varying degrees from 2015 to 2018, the total proportion of the two species has always exceeded 50\%. In other words, the important position of herring and mackerel cannot be replaced. Furthermore, considering that these two kinds of fish are the main catches of small fishing companies, it is necessary to help them make some strategy changes so as to fit in with the migration of herrings and mackerels.

Fishing companies always take profit and long-term development as their overall goals. The overall goal can be divided into the following major factors: fish resources in the sea, configuration of fishing equipment, operation pattern and natural environment factors. According to the proposed strategy, a three-layer structure (objective layercriteria formation - solution layer) Analytic Hierarchy Process model is established.

Based on the future forecast of the two fish species and the changes in sea surface temperature, the following suggestions are put forward:

- Suggestion 1: Relocate some or all of the fishing company's assets from a current location in a Scottish port to closer to the places that both fish species are moving;

- Suggestion 2: Use a certain proportion of small fishing vessels that can not only operate without land-based support for a period of time, but also ensure the freshness and high quality of the catch;

- Suggestion 3: Pay more attention to predictions of sea environment changes [8] so as to choose the right fishing boat according to the weather. 
A Evaluation Model about Development Strategy of Fishery Companies Based on AHP Method
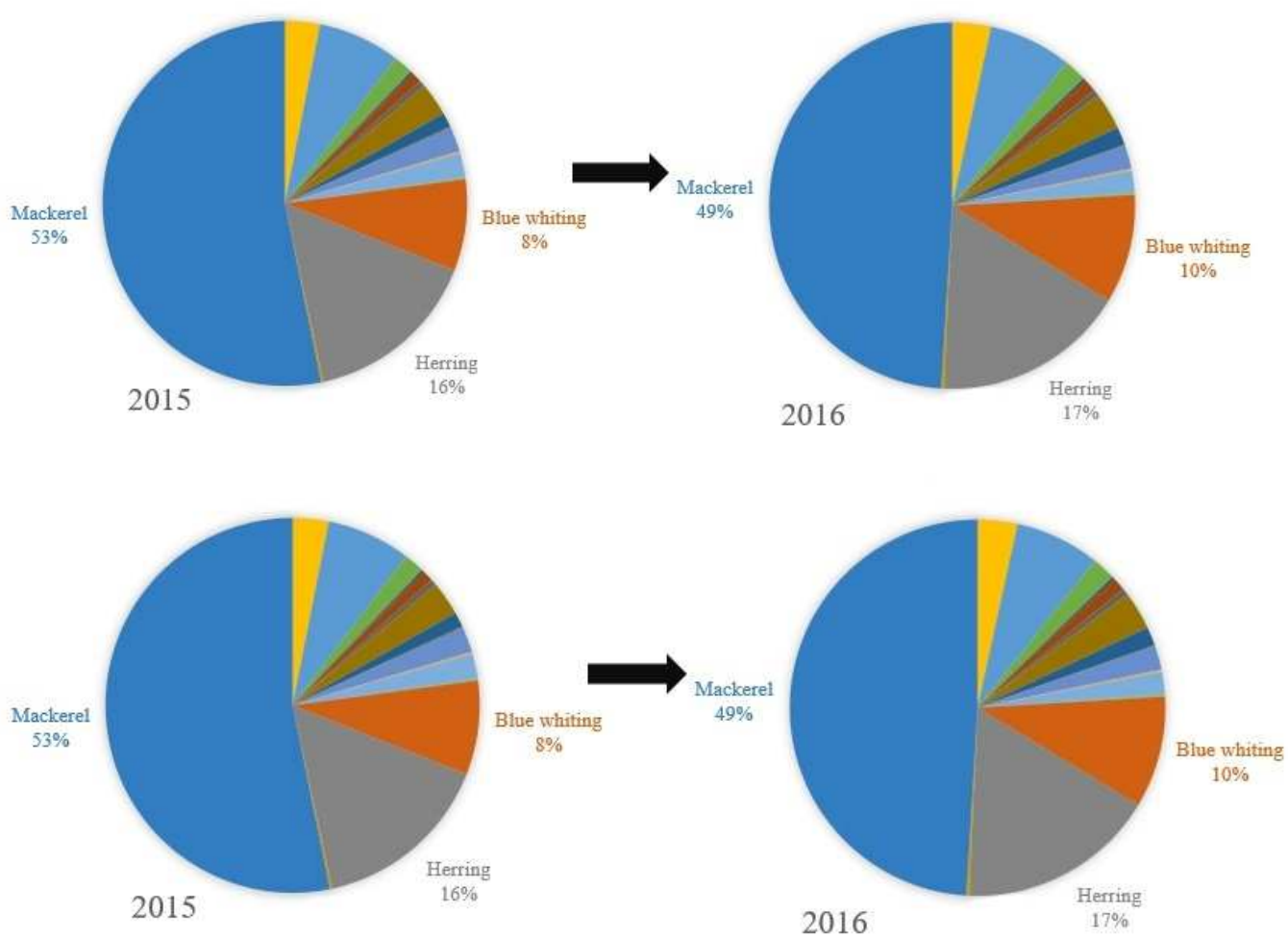

Figure 1: Percentage of Scottish vessels' landings by species type

\subsection{The structure of AHP model}

According to the above analysis, we build the following three-layer AHP model [9].

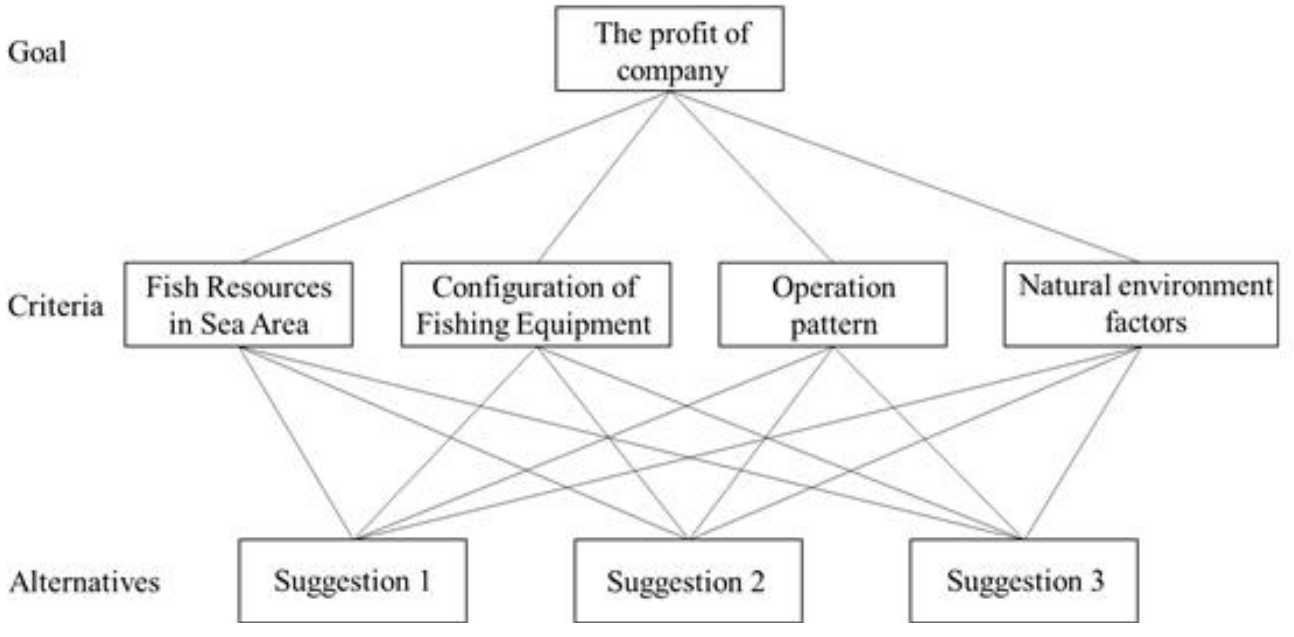

Figure 2: The structure of Analytic Hierarchy Process 


\section{Jia-feng Xiao and Zhi-xu Huang}

\subsection{Discriminant matrix}

By analyzing the relevant information of the four indicators of the criterion layer, the discriminant matrix is established as follows:

$$
A=\left[\begin{array}{cccc}
1 & 2 & \frac{3}{2} & 2 \\
\frac{1}{2} & 1 & \frac{1}{2} & \frac{1}{3} \\
\frac{2}{3} & 2 & 1 & \frac{2}{3} \\
\frac{1}{2} & 3 & \frac{3}{2} & 1
\end{array}\right]
$$

\subsection{Consistency test}

By solving the characteristic roots of the discrimination matrix A, it is easy to obtain the maximum characteristic root $r=4.1179$, and we use the following Saaty consistency index:

$$
C I=\frac{(r-n)}{n-1}
$$

It can be calculated that $\mathrm{CI}=0.0393$. We can also get RI according to the Saaty's random consistency table and then calculate the value of CR:

$$
C R=\frac{C I}{R I}=0.0437<0.1
$$

Consequently, the test is passed.

\subsection{Calculation of index weight vector}

We can eliminate the difference between the indicators through normalization to obtain the indicator weight vector as follows:

$$
w=(0.3693,0.1250,0.2202,0.2855)
$$

\subsection{Calculation of scheme layer weight vector}

We construct a positive and reciprocal matrices for each scheme layer to the criterion layer separately, and then obtain the index vector of each matrix.

By using the criterion layer index as weight vector, the scores of each scheme are calculated as follows:

$$
\text { score }=(0.4270,0.2785,0.2944)
$$

The final scores of the three schemes are:

\section{Suggestion $1>$ Suggestion $3>$ Suggestion 2}

The difference between the three scores is small.

As for suggestion 1, we come to a conclusion that the distribution density of herring and mackerel directly affects the landing tonnage of the two fishes. Thus, our suggestion is that the port location should be moved to a place close to the migration of the two fishes, which will have a great economic promotion effect on the fishing company. 
A Evaluation Model about Development Strategy of Fishery Companies Based on AHP Method

However, since small fishing vessels are not the main types of fishing vessels for pelagic fish, the increase of the proportion of small fishing vessels will not have a significant effect on the economic improvement of small fishing companies.

For Suggestion 3, if more accurate data on sea weather is available, the fishing companies can choose more appropriate time and boats to catch, which will significantly increase the landing tonnage of herring and mackerel, and hence improve the economic development of the fishing company.

\section{Conclusion}

In a word, fishing companies should actively adjust their management strategies with the distribution of the fish shoals. At the same time, they should relocate the port to the places closer to herring and mackerel for accommodating the migration of herring and mackerel. Furthermore, the enhancement on the forecast of the sea environment is also a good way. Only by doing this can small fishing companies maintain a good economic development during northward movement of shoals of fish.

\section{REFERENCES}

1. M.Ping, A review of research based on bibliometric analytic hierarchy process, Journal of Economic Research, (32) (2018) 6-8.

DOI:10.3969/j.issn.16 73-291X.2018.32.003.

2. C.Jun and Y.Qi, Research on the construction of emergency fiscal expenditure performance evaluation index system - investigation based on fuzzy analytic hierarchy process, Finance and Trade Economics, (3) (2013) 21-31.

3. W.Jun and W.Jiangbo, Research on the evaluation of urban competitiveness based on AHP - taking six cities in Anhui North Anhui as an example, Architecture and Culture, (5) (2020) 167-168.

4. Y.Liming, S.Haiyi and L. Ning, Research on comprehensive evaluation of college students based on improved Analytical Hierarchy Process, Innovation Education Research, 7(3) (2019) 275-281.

DOI: 10.12677/CES.2019.73048.

5. C.Guo, Comprehensive evaluation of small reservoir safety based on analytic hierarchy process, Water Conservancy Science and Technology and Economy, 26(5) (2020) 44 - 50.

DOI: $10.3969 /$ j.issn.1006-7175.2020.05.011.

6. W.Jinwu, Fish migration prediction based on long-short-term memory network and fuzzy comprehensive evaluation, Computer Programming Skills and Maintenance, 4 (2020) 129-132.

7. gov.scot. Scottish species landing data. https://www.gov.scot/news/provisionalscottish-seafisheries-statistics-2018/

8. Y.Liu, Impact of climate change on chinese coastal fishery production (in Chinese), Chinese Journal of Agrometeorology, 21(4) (2000) 1-5.

9. J.Yan, Analytic Hierarchy Process model and evaluation of urban public building fire prevention system, Anhui Architecture, 26 (10) (2019) 37-40.

DOI:10.16330/j.cnki.10077359.2019.10.012. 